\title{
AN EXPERIMENTAL STUDY OF HYDRAULIC BREAKWATERS
}

\author{
Lorenz G. Straub \\ Director, St. Anthony Falls Hydraulic Laboratory \\ John B. Herbich \\ Assistant Professor, Iehigh University \\ C. E. Bowers \\ Research Associate, St. Anthony Falls Hydraulic Laboratory
}

\section{INTRODUCTION}

A hydraulic or water-jet breakwater is formed by forcing water through a series of nozzles mounted on a pipe which is installed perpendicular to the direction of the incident waves. The jets create a surface current which results in breaking of the incident wave. Apparently, this effect is primarily responsible for attemuation of the incident wave. An earlier development, the pneumatic breakwater, operates on a similar principle with a horizontal surface current induced by rising air bubbles.

It may be noted in Fig. I that the pneumatic breakwater generates two surface currents. One opposes the incident waves, and the second or leeward current has no appreciable detrimental effect on the waves with the result that about half of the energy supplied to the system is wasted. This suggested the possibility of utilizing horizontal water jets in which all of the surface current could be directed against the incident wave. Of primary interest was the relative power requirements of the hydraulic and pneumatic types. This paper presents the results of both small- and large-scale tests of the hydraulic type. Iarge-scale tests of the pneumatic type are also planned but results are currently not available for comparison.

The concept of using a portable device for protection against waves is not new. Philip Brasher (1907) patented a method of attenuating waves by forcing compressed air through a submerged, perforated pipe. Prototype installations at Million Dollar Pier, Atlantic City, (1908) and at EI Segundo Pler, Califormia, (1915) were described as successful in damping waves. Other reports published on pneumatic breakwaters include Bogolepoff (1930), Platzer (1938), Schijf (1940), Taylor (1943 and 1955), Carr (1950), Evans (1954 and 1955), Wetzel (1955), Hensen (1955 and 1957), Kyushu University (1955), Herbich et al (1956), and Snyder (1957); but some are conflicting and controversial. Carr, Evans, and more recently, Snyder conducted tests on the hydraulic breakwaters in addition to the studies reported herein.

\section{EXPERIMENTAL STUDIES}

\section{GENERAL COMMENTS}

The major part of the study was essentially twomdimensional in character and a single manifold was used in most of the tests. 


\section{COASTAL ENGINEERING}

The primary objective was the procurement of information concerni the effect of various parameters on wave attenuation, which is defined as $I-\mathrm{H}_{\mathrm{T}} / \mathrm{H}_{\mathrm{I}} \quad\left(\mathrm{H}_{\mathrm{I}}=\right.$ incident wave height and $\mathrm{H}_{\mathrm{T}}=$ transmitted wave height). Parameters which were varied include the wave length $I$, th wave height $H$, jet submergence $y$, jet area $a_{j}$, and jet discharge q. The horsepower and discharge required under various test condition were expressed in the form of dimensionless ratios as follows:

$$
\begin{aligned}
& \phi=\frac{\text { Horsepower per lineal foot of breakwater }}{\rho g^{3 / 2} L^{5 / 2}} \\
& \psi=\frac{\text { Discharge per Iineal foot of breakwater }}{L \sqrt{g d}}
\end{aligned}
$$

where $\phi$ is dimensionless power ratio, $\psi$ is dimensionless dischar ratio, $\rho$ is density of water in slugs per cubic foot, $g$ is acceleration due to gravity in feet per second ${ }^{2}$, and $d$ is water depth.

The horsepower was normally computed at the jets; for design pur. poses it would be necessary to add losses in the supply lines and manifold.

The two wave channels employed in these studies were, for practi purposes, geometrically similar. The small chamel is $2 \mathrm{ft}$ wide, $1 \mathrm{f}$. $3 \mathrm{in}$. deep, and $50 \mathrm{ft}$ long and the large channel is $9 \mathrm{ft}$ wide, $6 \mathrm{ft}$ deep, and $253 \mathrm{ft}$ long (Fig. 2). Both channels were equipped with goo wave absorbers. Capacitive wave-profile recorders were employed to measure the wave characteristics.

\section{EXPERTMENTAL RESULTS}

The data indicated that the power requirements of a hydraulic breakwater are primarily dependent upon wave length, water depth, wave steepness, submergence of the nozzles, spacing and size (or area of nozzles, and the number of manifolds.

\section{Effect of Wave Iength and Water Depth}

Experimental data were obtained in the large channel for $I / d$ values up to about 4.2 and in the small channel up to 5.6 . Considerable scatter occurred for values less than 1.0. Excluding these values, it appears that $\phi$, the horsepower ratio, is fairly constant for $I / d$ values up to about 2.0 and that it increases quite rapidly for $\mathrm{L} / \mathrm{d}$ values in excess of 2.0 . Figure 3 illustrates typical data for an attenuation of 100 per cent. In this instance th power requirements for a single manifold increase by a factor of 7 as the $I / d$ value is increased from 2.0 to 5.0 . 


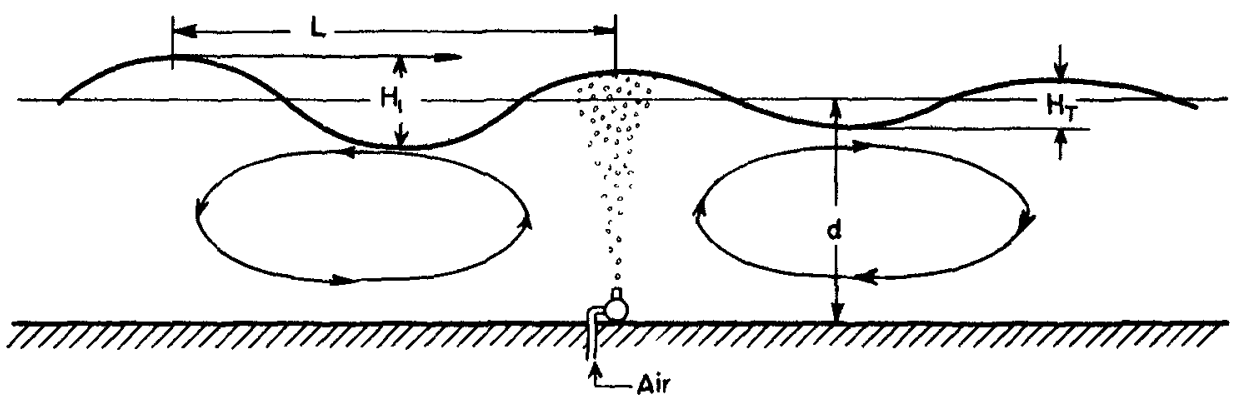

Pneumatic Breakwater

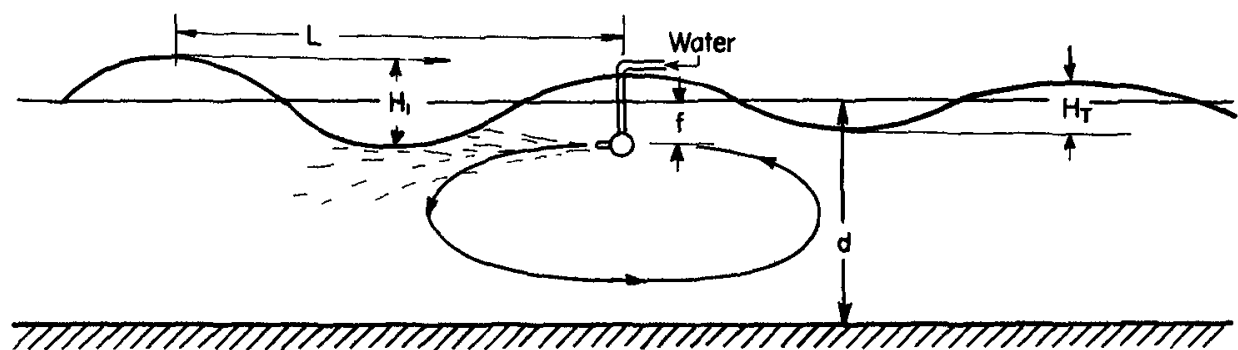

Hydraulic Breakwater

Fig. 1. Sketches Illustrating Pneumatic and Hydraulic Breakwaters.

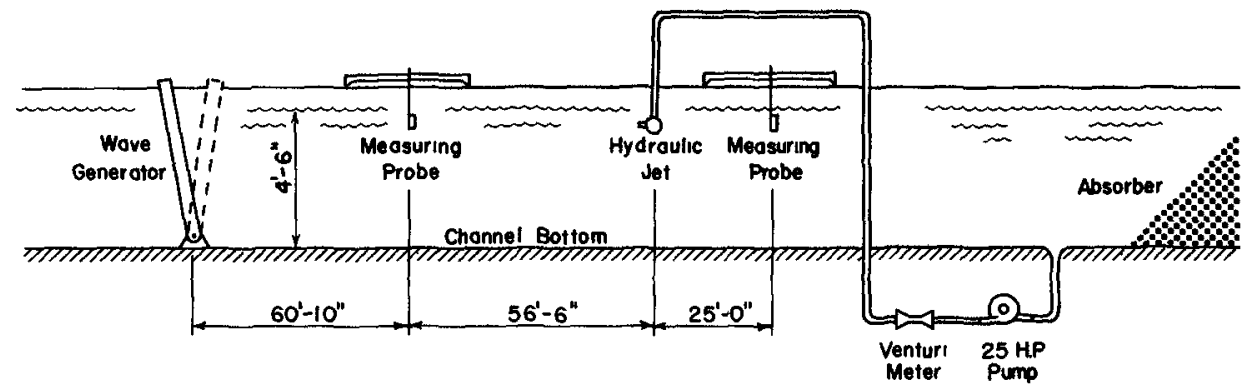

Fig. 2. Sketch of Test Installation in the Large Wave Channel. 
COASTAL ENGINEERING
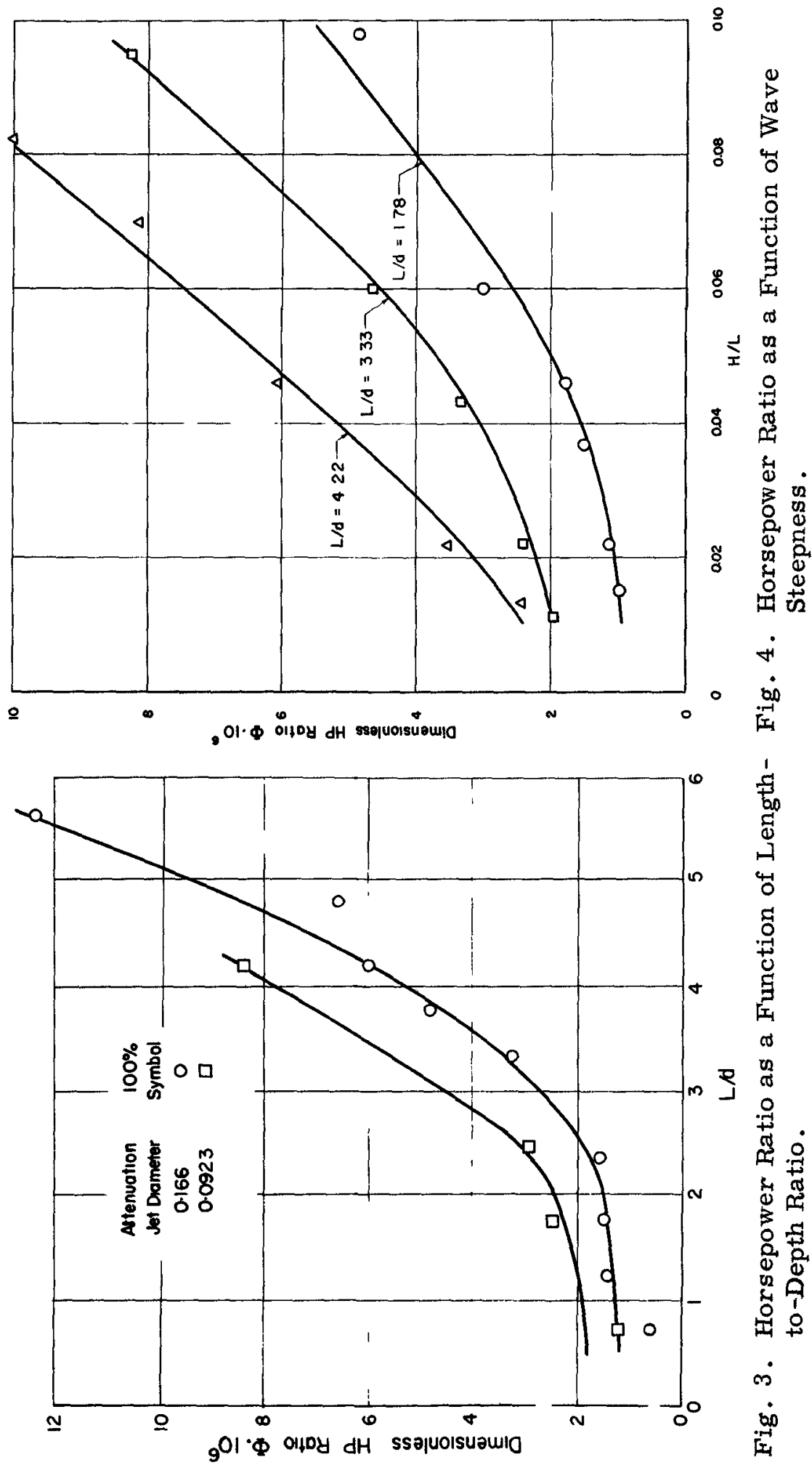

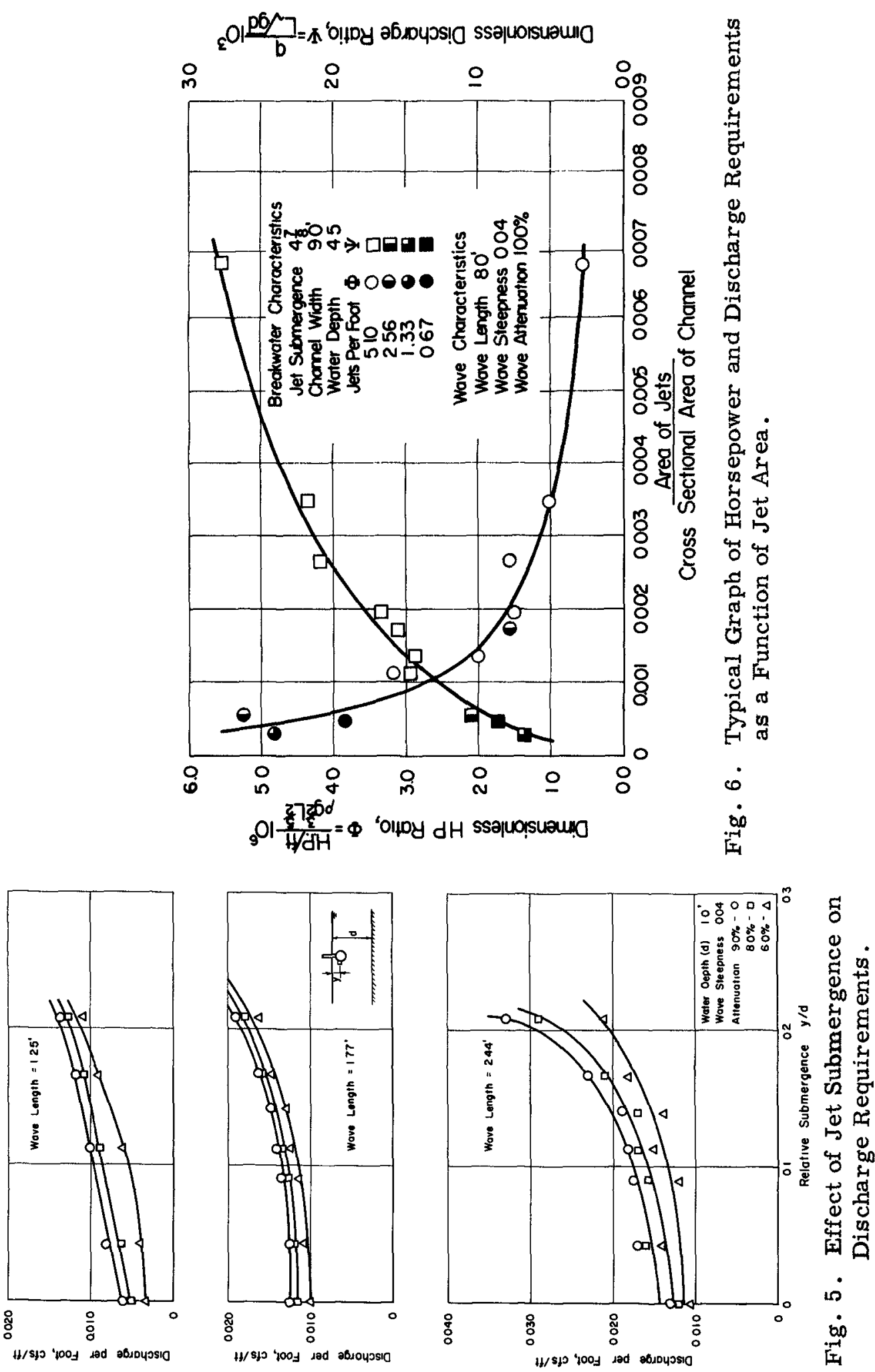


\section{COASTAL ENGINEERING}

\section{Effect of Wave Steepness}

Wave steepness has an important effect on power requirements. Figure 4 presents typical data for three $\mathrm{L} / \mathrm{d}$ values based on the small-scale tests. Considering the curve for an $I / d$ value of 3.33 , it may be noted that for an increase in wave steepness from 0.02 to 0.08 , a factor of 4 , the required horsepower ratio $\phi$ is increased by a factor of about 3 . However the true efficiency, that is, the ratio of attemuated wave energy to the jet energy, is considerably higher for the steep waves than it is for the shallow waves.

\section{Effect of Jet Submergence}

The results presented in Fig. 5 indicate that the zero submergence condition is the most efficient; however there may be objections to a prototype installation using this value, and the majority of tests were based on a relative submergence value $y / d$ of 0.091 . A slight correctj can be applied to such data by use of Fig. 5 if zero submergence is required.

\section{Effect of Jet Area}

One of the most important parameters affecting both the discharge and horsepower requirements is the jet area per lineal foot of breakwater. Jet area is dependent on two variables--jet spacing and jet size. During this study both the jet spacing and jet area were varied; large-scale tests covered spacings of $1.34,2.56$, and 5.11 jets per ft and a number of jet diameters between 0.422 and 1.047 inches. Four $\mathrm{L} / \mathrm{d}$ ratios ( $\mathrm{L}=$ wave length, $\mathrm{d}=$ water depth) were selected for the tests: $0.72,1.22,1.78$, and 2.44 . A typical summary graph for $\mathrm{L} / \mathrm{d}=$ 1.78 and 100 per cent attenuation is presented in Fig. 6. In this case the dimensionless horsepower ratio $\phi$ and dimensionless discharg ratio $\psi$ were plotted against the dimensionless jet area which is defined as

area of jets

cross-sectional area of channel

which is equal to

$\frac{a_{j}}{a_{c}}=\frac{\text { area of jets per foot }}{1 \times \text { depth of channel }}$

Figure 6 indicates that the discharge and power requirements are strongly dependent on the jet area. Low values of jet area are associa with a requirement for high power, high jet velocities, and low discharges. It appears that power requirements at the jets or nozzles wil probably decrease as the jet area is increased until the latter is equa to the cross-sectional area of the required surface current. Apparentl 

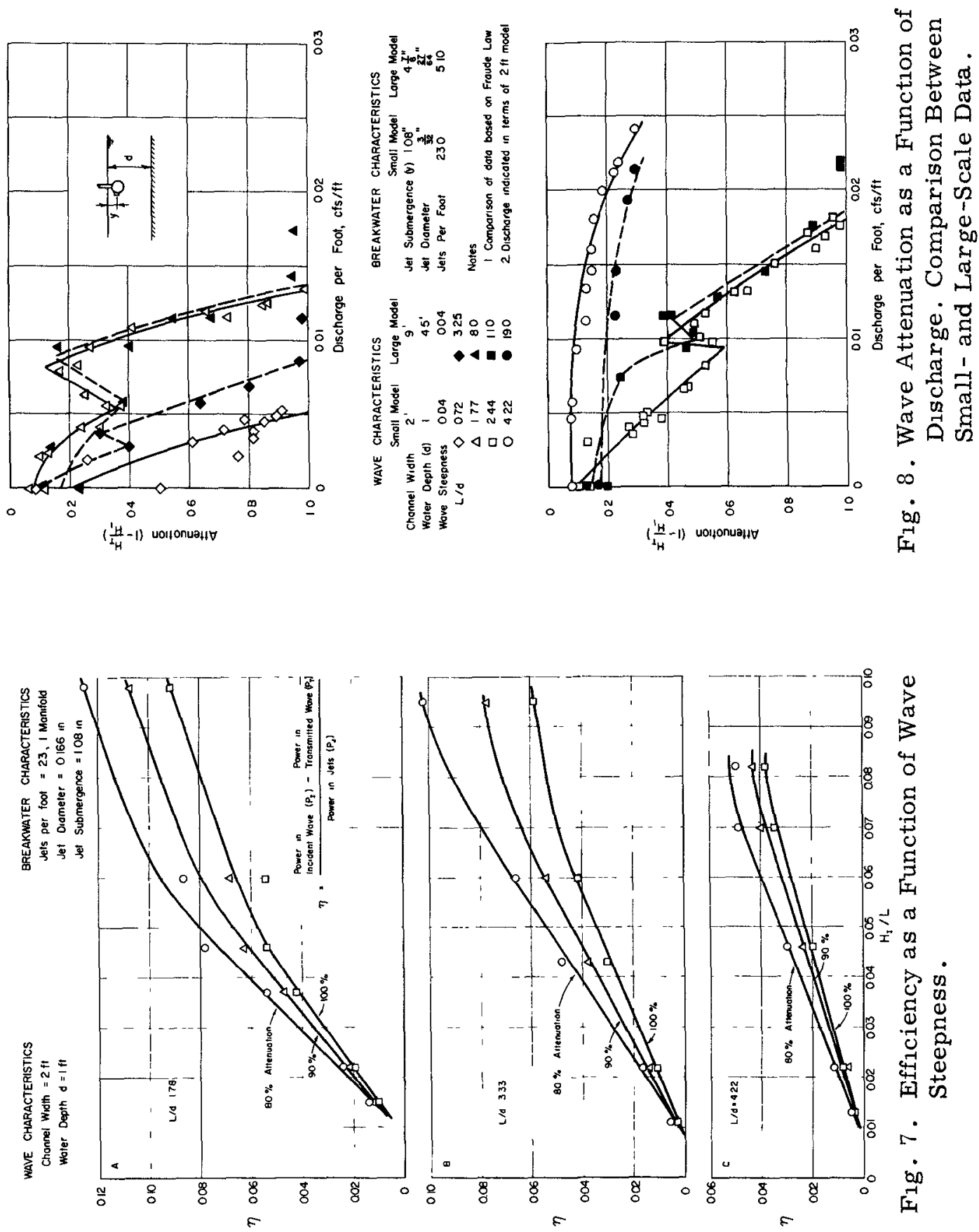


\section{COASTAL ENGINEERING}

the turbulent losses in the jets decrease as the jet velocity decreases, resulting in better efficiencies. However, as the jet area is increased the required discharge is increased; as a result, it would be necessary to use larger manifolds and supply pipes or provide for larger losses in these components.

\section{Efficiency}

As noted in the section on wave steepness, more power is required to attenuate relatively steep waves than flat waves; however the efficiency of the system $\eta$ is much higher for the steep waves than it is for the flat waves. The efficiency is defined as

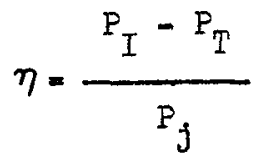

where $P_{I}$ is the power in incident wave, $P_{T}$ is the power in transmitted wave, and $P_{j}$ is the power in the hydraulic jets.

Figure 7 illustrates experimental data on efficiency. For the one manifold system, the efficiency varies with steepness, attenuation, and relative wave length. For attenuations of 80 to 100 per cent, the maximum efficiency obtained was only about 12 per cent.

\section{Scale Effect}

The small and large wave channels, being geometrically similar, were ideally suited for a scale-effect study. For the purpose of comparison of small- and large-scale models, it was assumed that gravity and inertia forces are of primary importance in relating the two models and, consequently, that Froude's law governs. The Froude number may be expressed as

$$
F^{\prime}=\frac{C}{\sqrt{g d}}
$$

where $c=$ wave celerity, $g=$ acceleration of gravity, and $d=$ depth of water.

Consequently, the length ratio for the two models is $I_{r}=1 / 4.5$, the discharge ratio is $Q_{r}=I_{r} 5 / 2$, and the power ratio is $P_{r}=I_{r} 7 / 2$

Figure 8 illustrates comparative discharge data expressed in terms of the small model. The preceding formulas were used to reduce the large-scale data to the appropriate conditions. It may be noted that data in the low-attenuation region exhibited considerable scatter and that the curves had a pronounced discontinuity; the latter may have resulted from a variation in the mechanism of energy loss as the jet 

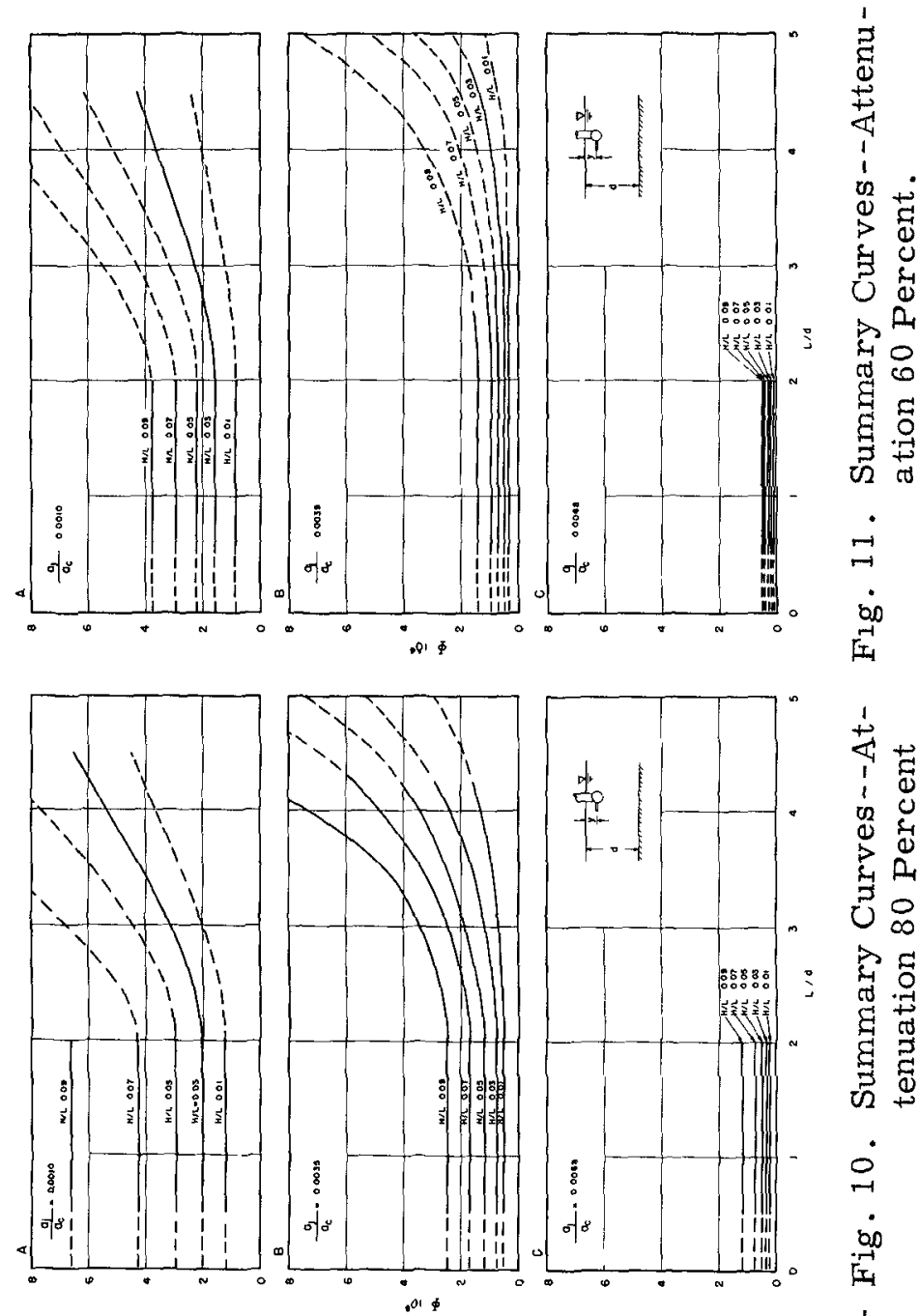

$\begin{array}{cc}1 \\ + \\ 4 & \\ 1 & 0 \\ 1 & 0 \\ 02 & 0 \\ 0 & 0 \\ 0 & 0 \\ 0 & 0 \\ 5 & 0 \\ 0 & 0\end{array}$

$$
\text { 究. }
$$

웅
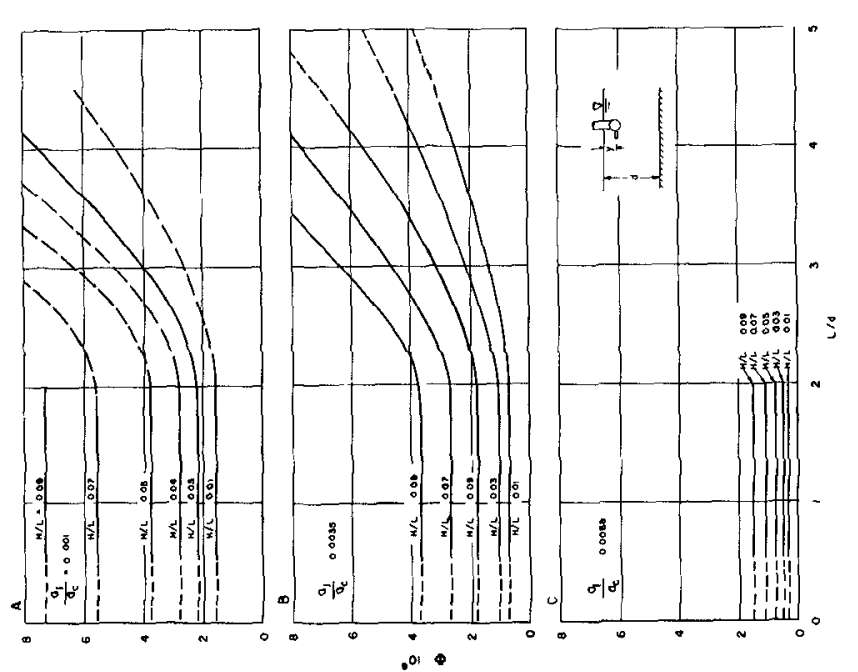

它

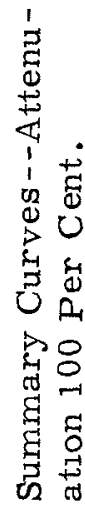

o

$\dot{\infty}$

$\underset{\dot{I}_{1}}{\dot{\infty}}$ 


\section{COASTAL ENGINEERING}

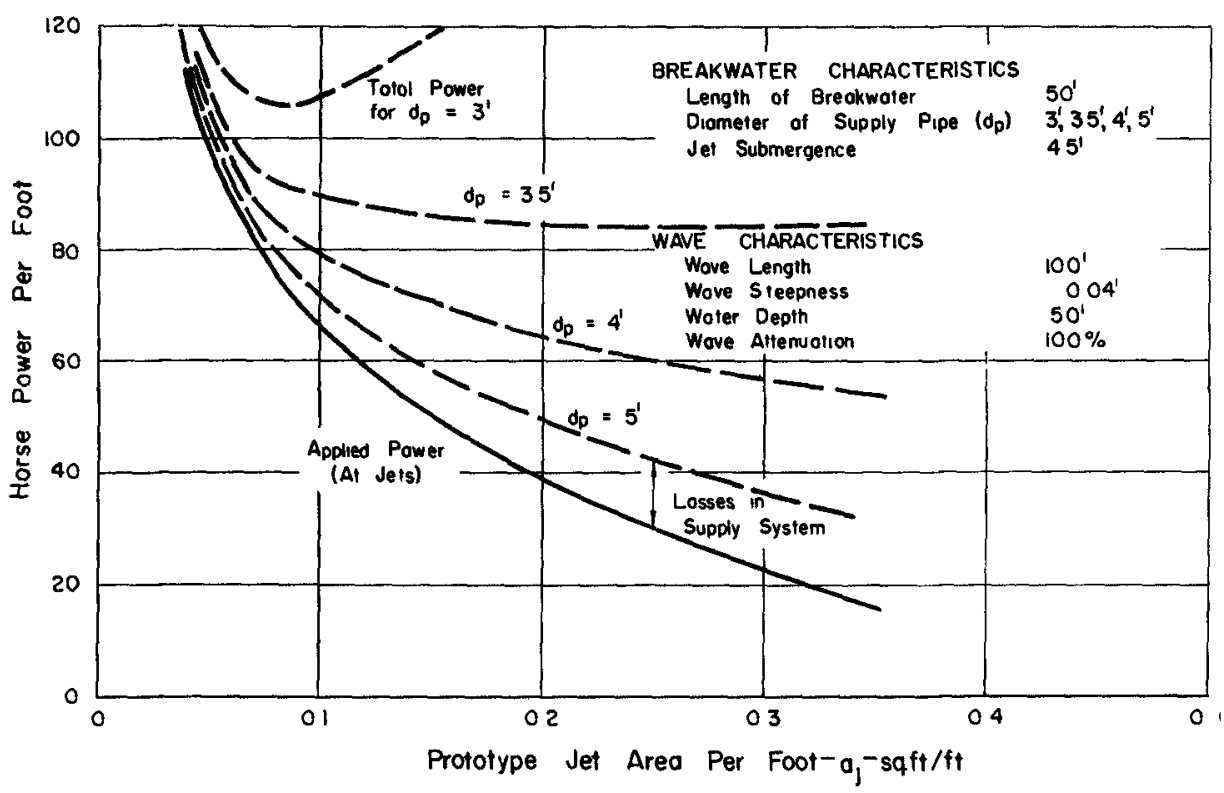

Fig. 12. Horsepower Requirements for a Typical Hydraulic Breal water.

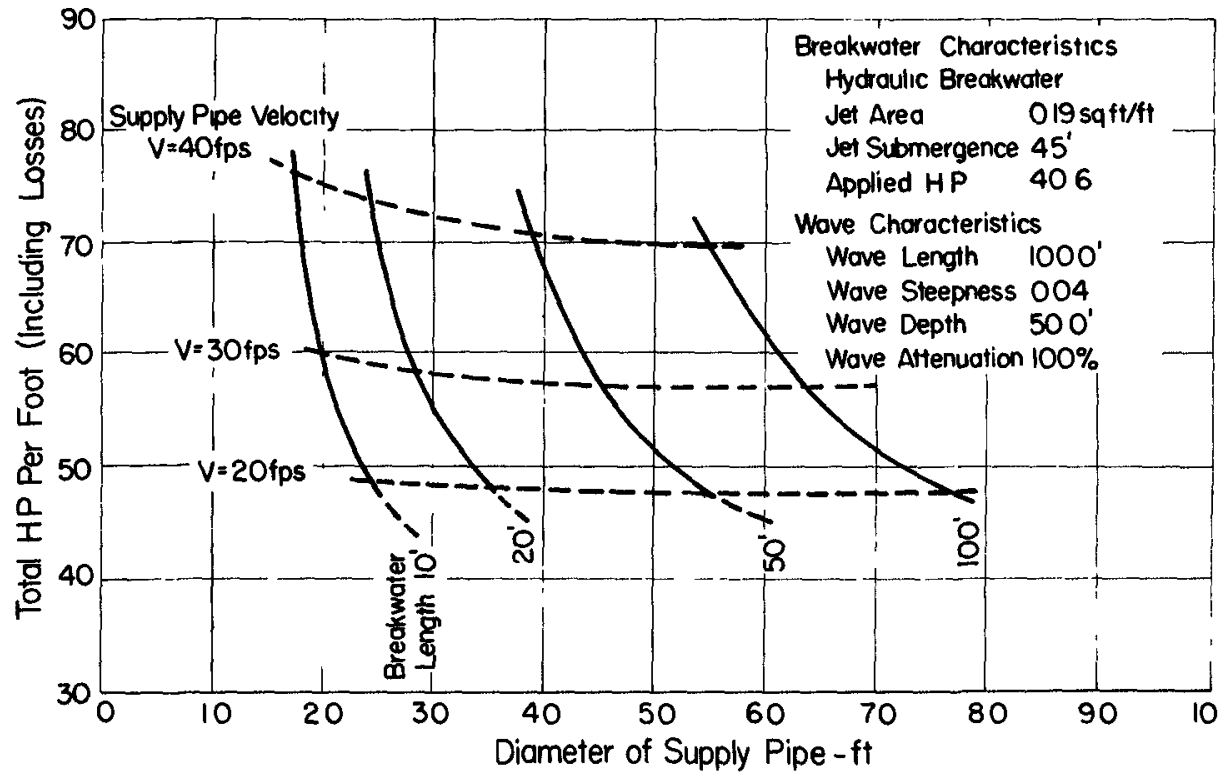

Fig. 13. Typical Relationship Between Power Requirements and Diameter of Supply Pipe. 


\section{AN EXPERIMENTAL STUDY OF HYDRAULIC BREAKWATERS}

discharge was varied. Considering the data for attenuations in excess of 50 per cent and $\mathrm{I} / \mathrm{d}$ values in excess of 1.0 , agreement between the data for two models is quite good. It was concluded that little, if any, evidence of scale effect existed for the 1:4.5 scale ratio of the two sets of tests. It is belicved that these are the first tests on two different sizes of models of the hydraulic breakwater.

\section{SUMVIARY CUPVES}

Power requirements at the jets are summarized in Figs. 9 through 11 in dimensionless form. The faired curves were based primarily on the large-scale tests in the region of $1<\mathrm{I} / \mathrm{d}<2.5$ and upon smallscale tests for $L / d>2.5$. The dimensionless power ratio $\phi$ can be determined for selected values of $L / d, E / L, a_{j} / a_{c}$, and attenuation.

The required discharge per lineal foot of breakwater can be computed by the following formula:

$$
q=58.58 a_{j}^{2 / 3} \phi^{1 / 3} I^{5 / 6} \text { in cfs per ft }
$$

where 58.58 is a constant $=1100^{1 / 3} \mathrm{~g}^{1 / 2}$ and $\mathrm{I}$ is the wave length.

The value of $a_{j}$ can be computed from the equation

$$
a_{j}=\frac{a_{j}}{a_{c}} d
$$

after the depth is selected. The ratio $a_{j} / a_{c}$ is given in each graph.

As noted before, the value of $\phi$ is the applied power at the end of the nozzles. The total power of the system will involve losses in the manifold and supply system, in addition to the applied power. To illustrate the comparative importance of losses in the supply system and the effect of jet area, computations were made for an arbitrary set of condj.tions involving a wave length of $100 \mathrm{ft}$, water depth of $50 \mathrm{ft}$, and a wave steepness of 0.04 . Various pipe sizes were considered. As a hypothetical case, it was assumed that the pump or compressor was located about $10 \mathrm{ft}$ above the water surface and $20 \mathrm{ft}$ to the lee side. Several values of breakwater length to be supplied from one compressor were considered. Piping losses were computed for various discharges using the equation

$$
H_{L}=\left(f \frac{\ell}{d p}+k\right) \frac{v^{2}}{2 g}
$$


where $H_{L}$ is head loss in feet, $f$ is friction coefficient $(=0.01)$, $\ell$ is length of pipe, $d_{p}$ is pipe diameter, $V$ is velocity of flow ir pipe, and $k$ is a total coefficient loss for bends, nozzles, and tees ( $k$ was assumed $=1.0$ ). It was also assumed that the supply pipe had as effective length of $60 \mathrm{ft}$, including an assumed allowance for the mani. fold.

Figure 12 presents the curve for applied horsepower at the nozzle as a function of jet area and curves of total horsepower including losses in the supply system for pipe and manifold diameters of $3.0,3$. ! 4.0 , and $5.0 \mathrm{ft}$; the losses in the supply system were computed for a breakwater length of $50 \mathrm{ft}$ per supply pipe, and the result divided by 50 to give horsepower per unit length of breakwater. Similar curves could be computed for various effective lengths of breakwater to assis in the selection of optimum jet area.

Figure 13 was prepared as a second illustration of the effect of pipe size and length of breakwater supplied by a single pipe. A jet area of $0.19 \mathrm{sq} f t$ per $f t$ was used, which is near the minimum total power requirement for a 3.5-ft pipe and 50-ft length of breakwater. The solid curves indicate total power as a function of pipe diameter for various lengths of breakwater supplied by a single pipe. The dotted curves indicate the resulting velocity in the supply pipe.

\section{CONCIUSIONS}

1. Horsepower and water-discharge requirements for the hydraulic breakwater are dependent upon wave characteristics such as length, height, and water depth, and breakwater characteristics such as spacin and size of nozzles, submergence of nozzles, and the number of manifolds.

2. A single-manifold hydraulic breakwater is quite effective for deep-water waves $(I / d<2)$, but its effectiveness decreases with increasing $\mathrm{L} / \mathrm{d}$ ratios.

3. For high values of attenuation, more power is required to attemuate the steep waves; however, the efficiency of the system based on the ratio of the difference between incident and transmitted wave energy to the jet energy is much higher for the steep waves than it is for the flat waves.

4. Zero submergence of the nozzles appears to be most efficient for the range of wave lengths tested; however, the differences in discharge requirements are not large for values of $\mathrm{y} / \mathrm{d}$ between 0 and 0 .

5. Power and discharge requirements at the nozzles are dependent upon the area of jets per unit length of manifold. As the area is increased, the power decreases, and the discharge increases. As losses in the pumping and supply system are dependent on the discharge, the supply system must be analyzed along with the manifold and jet system in order to determine the optimum jet area. 


\section{AN EXPERIMENTAL STUDY OF HYDRAULIC BREAKWATERS}

6. Comparative data on the hydraulic breakwater obtained in the large and small channels (scale ratio 1:4.5) agree quite well when compared on the basis of Froude's law for values of $I_{1} / d$ between 1.22 and 1.78. This would indicate that little scale effect exists over this range and tends to substantiate extrapolation of the data to the prototype condition.

7. There are preliminary indications that a several-manifold hydraulic breakwater producing a thicker surface current might require less power at the jets and higher discharges than a breakwater with a single manifold for large $\mathrm{L} / \mathrm{d}$ values, but additional tests would be required to determine the optimum efficiencies of several-manifold breakwaters for a given range of $I / d$ values.

8. Iimited comparisons with Taylor's theory indicated the theoretical value of surface-current velocity usually occurred at a distance of one or two wave lengths from the breakwater for an experimental wave steepness of 0.01 . The comparison is somewhat arbitrary as the theory does not consider wave steepness.

9. Snyder's experiments show fairly good agreement with the tests described herein for high values of attenuation. For low values of attenuation Snyder's experiments resulted in somewhat larger discharges than St. Anthony Falls data indicate.

\section{ACKNOWLEDGMENT}

This investigation was sponsored by the Office of Naval Research and conducted at the St. Anthony Falls Hydraulic Laboratory.

\section{REFERENCES}

Anon. (1916). The Brasher Air Breakwater: The Engineer, p. 4I4.

Anon. (1916). Severe Test of the Brasher Air Breakwater: Compressed Air Magazine.

Bogolepoff, J.A. (1937). Der Pressluft-Wellenbrecher: Bulletin of the Permanent International Association of Navigation Congresses.

Platzer, Sven (1938). Pneumatiska vågbrytare: Teknisk Tidskrift, vol. 68, pp. 105-109.

Schijf, J. B. (1940). Het vernietigen van golven door het inspuiten van lucht (Pneumatische golfbrekers): De Ingenieur, vol. 55, pp. 121-125.

Taylor, G. I. (1943). Note on possibility of Stopping Sea Waves by Means of a Curtain of Bubbles: Admiralty Scientific Research Department, ATR /Misc/ 1259.

Carr, John H. (1950). Wiobile Breakwater Studies: California Institute of Technology, Hydrodynamics Laboratory, Report No. N-64.2. 


\section{COASTAL ENGINEERING}

Evans, J. T. (1954). Pneumatic and Similar Breakwaters: British Transport Commission, Docks and Inland Waterways, Report No. 2l, $23 \mathrm{pp}$.

Wetzel, J. M. (1955). Experimental Studies of Pneumatic and Hydraulic Breakwaters: University of Vinnesota, St. Anthony Falls Hydraulic Laboratory Project Report No. 46, 61 pp.

Taylor, G. I. (1955). The Action of a Surface current Used as a Breakwater: Proceedings of the Royal Society, A, vol. 23l, pp. 466-478.

Evans, J.T. Pneumatic and Similar Breakwaters: Proceedings of the Royal Society, A, vol. 231, pp. 457-466.

Hensen, Walter (1955). Modelversuche mit pneumatischen Wellenbrechern: Mitteilungen der Hannoverschen Versuchanstalt fur Grundbau und Wasserbau, Franzius Institut der Technischen Hochschule Hannover. Heft 7, pp. 179-214.

Anon. (1956). Pneumatic Breakwater Trials: The Dock and Harbour Authority, No. 426, vol. 36, p. 364 .

Iaurie, A. H. (1955). The German Experiments on Pneumatic Breakwaters: The Dock and Harbour Authority, No. 416, vol. 36, pp. 61-64.

Anon. (1956). On the Study of a Pneumatic Breakwater, vol. II, III, and IV. Reports of Research Institute for Applied Mechanics, Kyushu University.

Herbich, John B., Jurgen Ziegler, and C. E. Bowers. (1956). Experiment: Studies of Hydraulic Breakwaters. University of Minnesota, St. Anthony Falls Hydraulic Laboratory Project Report No. 51, 103 pp.

Hensen, W. (1957). Erprobungen von pneumatischen Wellenbrechern in Nodel und in der Natur: Mitteilungen der Hannoverschen Versuchanstalt fur Grundbau und Wasserbau, Franzius Institut der Technischen Hochschule Hannover. Heft 10, pp. 183-209.

Snyder, C. M. (1957). Model Hydraulic Breakwater Studies: Wave Research Laboratory, University of Califormia, $30 \mathrm{pp}$. 